\title{
Laterality in tool manufacture by crows
}

\section{Neural processing and not ecological factors may influence 'handedness' in these birds.}

$\mathrm{N}$ ew Caledonian crows (Fig. 1) fashion tapered tools from either the left or the right edge of the long narrow leaves of pandanus trees or screw pines ${ }^{1,2}$, which they use to extract invertebrates in rainforest vegetation $^{2}$. Although right-handedness is thought to be uniquely human ${ }^{3}$, we show here that crows from different localities display a widespread laterality in making their tools, indicating that this behaviour is unlikely to be attributable to local social traditions or ecological factors. To our knowledge, this is the first demonstration of species-level laterality in manipulatory skills outside humans.

We can detect laterality in the manufacture of stepped tools (Fig. 2a) by New Caledonian crows (Corvus moneduloides) because this differs according to whether the left or the right leaf-edge is used ${ }^{1}$. Birds carry out a well-defined sequence of precise cutting and ripping actions on both edges, with bill action being away from the tree right to left (left edges) or left to right (right edges). The right side of the head is generally towards the leaf edge in left-edge usage, and the left side in right-edge usage. A tool's finished shape is recorded in its unmistakable 'counterpart', the outline remaining on the leaf edge (Fig. 2a).

We collected 3,727 stepped-tool counterparts from 733 pandanus trees at 19 sites scattered throughout mainland Grande Terre, New Caledonia, the only island where crows

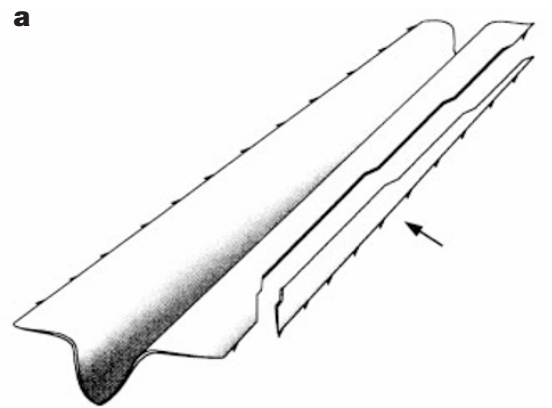
trunk: they must therefore work from either

are known to make these tools. The sites were mostly at least $10 \mathrm{~km}$ apart and distributed along $300 \mathrm{~km}$ of the narrow, 400-km-long island at altitudes of $160-1,600 \mathrm{~m}$ above sea level. This sampling covered the geographical range of pandanus-toolmaking (G. R. H., personal observation).

The crow's use of left or right leaf-edges depends in part on the direction in which the leaves spiral. Clockwise-spiralling leaves provide easier access to left edges, and anticlockwise-spiralling leaves provide easier access to right edges. This access effect was overridden, however, by an island-wide preference for manufacturing tools from left edges (Fig. 2b).

Population-level footedness in manipulating food while feeding is known in parrots ${ }^{4}$. In great apes, population-level handedness has been reported in several manipulative activities in wild gorillas ${ }^{5}$ (Gorilla g. beringei) and in captive chimpanzees (Pan troglodytes) ${ }^{6-8}$, but has not been shown so far in chimpanzees in the wild ${ }^{9,10}$. Although there have been no systematic comparisons, it has been suggested that the level of complexity of a motor task and the associated neural-processing demands may correlate with the degree of lateralization ${ }^{8,11}$.

The rather simple nature of chimpanzees' tool-making contrasts with the greater complexity of crows' stepped-tool manufacture ${ }^{1}$. The shape of stepped tools is highly regular and mostly determined by the crows themselves, rather than by the raw material, imply-

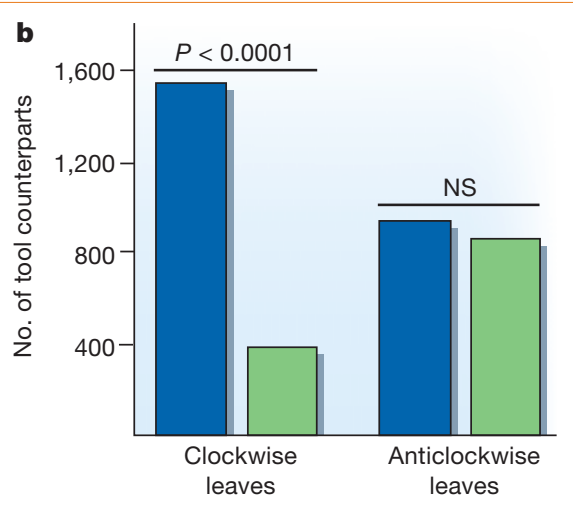

Figure 2 Lateralization in the manufacture of stepped tools from Pandanus sp. leaves by New Caledonian crows. a, A stepped tool (arrow), together with its counterpart shape on the left edge of a section of pandanus leaf (about $5 \mathrm{~cm}$ wide). Pandanus leaf rips easily along the strong, longitudinally parallel fibres, but must be cut laterally across the fibres. The tool is removed from right to left, beginning at the pointed end. Stepped-tool counterparts averaged $18.5 \pm 6.30 \mathrm{~cm}$ long (mean \pm s.d.m., $n=3,418$ ) and $0.84 \pm 0.24 \mathrm{~cm}$ wide $(n=3,128)$. $\mathbf{b}$, The number of tool counterparts on the left (blue bars) and right (green bars) edges of leaves for each leaf-spiral direction. A $2 \times 2$ contingency test on the data (edge $\times$ spiral direction) found a significant access effect due to leaf-spiral direction ( $G$-test of independence: $\left.G_{1}=330.3, P<0.0001, n=3,727\right)$, but there still exists a highly significant preference $\left(\chi_{1}^{2}=430.3, P<0.0001\right.$, $n=3,727)$ for manufacturing tools on left edges $(n=2,463)$ rather than right edges $(n=1,264)$. As individual birds are likely to have contributed more than one counterpart, this sample size is inflated. A conservative alternative is to treat each site as the unit of analysis. A Wilcoxon signed-ranks, matched-pairs test showed that the left-edged bias was still significant across the 19 sites ( $T=44$, two-tailed $P<0.05, n=19)$. Sample sizes for tool counterparts varied between sites (196.2 $\pm 120.8, n=3,727)$, but the number of trees sampled with clockwise $(n=369)$ and anticlockwise $(n=364)$ leaves were almost identical $(38.6 \pm 24.4$ trees per site, $n=733)$.

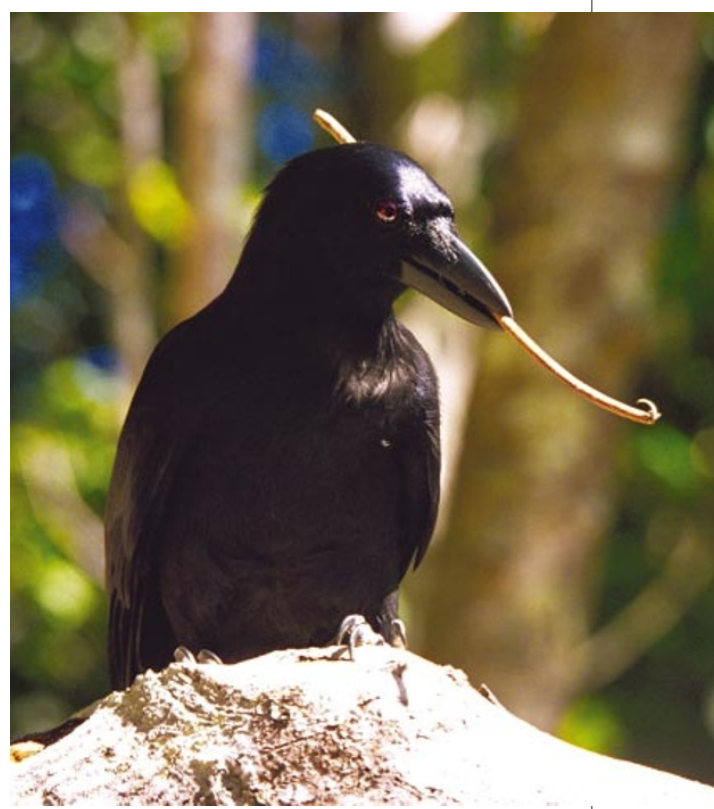

Figure 1 New Caledonian crow. These birds make tools to probe for insects, including the 'crochet' tool illustrated.

ing that a neural programme is involved in their manufacture ${ }^{1}$. Laterality in crows may therefore reflect the complexity of steppedtoolmaking and a specialization of the righteye/left-hemisphere system for non-spatial, sequential actions, as previously demonstrated in birds and mammals .

It has been proposed that right-handedness in humans may be a consequence of the evolution of language, which is also predominantly left-hemispheric ${ }^{3}$. Our results favour the more general possibility that species-level lateralization is an adaptation for the efficient neural programming of complex sequential processing $^{8,12}$, of which language and righthandedness in humans and stepped-tool manufacture in crows are examples.

Gavin R. Hunt, Michael C. Corballis,

Russell D. Gray

Department of Psychology, University of Auckland, Auckland 92019, New Zealand

e-mail: grhunt10@hotmail.com

1. Hunt, G. R. Proc. R. Soc. Lond. B 267, 403-413 (2000).

2. Hunt, G. R. Nature 379, 249-251 (1996).

3. Corballis, M. C. The Lopsided Ape: The Evolution of the Generative Mind (Oxford University Press, Oxford, 1991)

4. Harris, L. J. Can. J. Psychol. 43, 369-396 (1989).

5. Byrne, R. W. \& Byrne, J. M. E. Cortex 27, 521-546 (1991).

6. Hopkins, W. D. Psychonom. Bull. Rev. 3, 449-457 (1996).

7. Hopkins, W. D. \& Leavens, D. A. J. Comp. Psychol. 112, 95-99 (1998).

8. Bradshaw, J. L. \& Rogers, L. J. The Evolution of Lateral Asymmetries, Language, Tool Use, and Intellect (Academic, San Diego, 1993).

9. McGrew, W. C. \& Marchant, L. F. Int. J. Primatol. 18, 787-810 (1997).

10. McGrew, W. C. \& Marchant, L. F. Behaviour 138, 329-358 (2001).

11. Fagot, J. \& Vauclair, J. Psychol. Bull. 109, 76-89 (1991).

12. Vallortigara, G., Rogers, L. J. \& Bisazza, A. Brain Res. Rev. 30, 164-175 (1999). 
where the only two species that showed increased mortality at depth (Diploria strigosa and Acropora cervicornis) were very rare. Baker's "acutely stressed" corals, however, recovered under the higher light levels of a shallow-water site $(2-4 \mathrm{~m})$. From this experimental design, we cannot unequivocally conclude that the improved survival of the acutely stressed corals was due to their adoption of a new mix of dinoflagellates after bleaching, or to improved recovery conditions at the shallow site. As light energy is critical to the survival of reef-building corals ${ }^{6}$, stressed corals might be expected to survive better when transplanted to a more sunlit site and less well after transfer to deep water, irrespective of bleaching.

The $\mathrm{ABH}$ assumes that bleached corals favour new host-symbiont associations that optimize survival, necessitating rapid evolutionary adaptation (that is, genetic change) by populations of reef-building corals and their symbionts ${ }^{3}$. Although Baker claims that bleaching offers an ecological opportunity for reef corals to rid themselves rapidly of suboptimal algae and to acquire new partners ${ }^{1}$, he relies on a molecular technique that is unable to distinguish newly invading genotypes from other rare genotypes that are already present in the host and which simply increase in proportion after conditions change. The latter is a phenotypic change (acclimatization) and, as such, is restricted in its provision of new genetic combinations for evolution.

We consider that the evidence in favour of the $\mathrm{ABH}$ remains scant in the absence of observations that the genotypes of symbionts in corals become more thermally robust during and after mass bleaching. Baker's finding that corals adopt a different mix of symbiont genotypes when moved from one light environment to another is an interesting addition to the well-known acclimatory responses of corals and their symbionts to changes in light quality and quantity ${ }^{7}$, but we cannot conclude that bleaching favours new host-symbiont combinations that guard populations of corals against rising sea temperature.

\section{Ove Hoegh-Guldberg, Ross J. Jones,}

\section{Selina Ward, William K. Loh}

Centre for Marine Studies, University of

Queensland, Queensland 4072, Australia

e-mail:oveh@uq.edu.au

1. Baker, A. C. Nature 411, 765-766 (2001).

2. Buddemeier, R. W. \& Fautin, D. G. BioScience 43, 320-326 (1993).

3. Ware, J. R., Fautin, D. G. \& Buddemeier, R. W. Ecol. Model. 84, 199-214 (1996).

4. Jones, R. J. \& Hoegh-Guldberg, O. Plant Cell Envir. 24, 89-100 (2001).

5. Hoegh-Guldberg, O. Mar. Freshwat. Res. 50, 839-866 (1999).

6. Muscatine, L. \& Cernichiari, E. Biol. Bull. Mar. Biol. Lab. Woods Hole 137, 506-523 (1969).

7. Falkowski, P. G. \& Dubinsky, Z. Nature 289, 172-174 (1981).
Baker replies - Hoegh-Guldberg et al. suggest that corals that were transplanted downwards died more frequently than those transplanted upwards because they were deprived of critical sunlight energy at depth. My argument went a step further by explaining why this energy is so critical for these transplanted colonies.

Because corals that were transplanted downwards did not bleach in response to reduced irradiance, they failed to exchange their 'high-light' algal symbionts for the more suitable 'low-light' algae that were already found in the deep-water colonies at this site (and/or at other sites nearby). As a result, they contained inappropriate algae for their new environment, which led to chronic stress and eventual mortality.

In contrast, corals that were transplanted upwards experienced severe bleaching as a result of increased irradiance. Consequently, suboptimal low-light algae were removed, allowing high-light algae to become dominant in the newly vacant hosts. Such corals survived well as a result, despite their initial bleaching. This explanation is particularly powerful because it unifies coral bleaching, symbiont change and host mortality.

Hoegh-Guldberg et al. suggest that my findings fail to support the $\mathrm{ABH}$ because they do not provide evidence of 'new' symbionts in transplanted corals. The $\mathrm{ABH}$ is not limited to this constraint. Regardless of the origin of replacement symbionts (which, as I pointed out, may "colonize" and/or "proliferate inside" hosts) or the proximate environmental causes of bleaching (for example, light or temperature), if bleached reef corals change the composition of their symbiont communities faster than unbleached corals, and if more rapid symbiont change proves beneficial, then bleaching has adaptive value. Even if adult colonies are unable to form symbioses with unusual or new algae (which is unlikely, given the recent discovery of some scleractinian coral colonies containing symbionts that are usually found in foraminifera ${ }^{1}$ ), cryptic populations of diverse symbionts may still occur at low abundance in many coral hosts ${ }^{2}$.

There is no field evidence that symbiont genotypes change after bleaching events because the necessary molecular investigations have not yet been undertaken. Despite this, one of the best available long-term data sets on mass coral bleaching and mortality reveals that far fewer corals in the far-eastern Pacific Ocean died after the 1997-98 El Niño event (0-26\%) than after the 1982-83 El Niño event (52-97\%; ref. 3), even though the magnitude and duration of sea-surface temperature anomalies in the region in 1997-98 exceeded those of 1982-83 (ref. 4). These observations indicate that surviving reef corals may be more resistant to recurrent thermal stress through having experienced earlier episodes of severe bleaching and mortality, as predicted by models of symbiont change ${ }^{5}$.

Furthermore, field experiments with bleached corals ${ }^{6}$ and laboratory studies of model invertebrate-algal symbioses ${ }^{7}$ support some of the assumptions of the $\mathrm{ABH}$. We should not mistake an absence of evidence for evidence of absence, and instead need to document worldwide patterns of coral-algal associations and their response to mass-bleaching events. The real question is not whether coral-algal associations can adapt by recombining, but rather how, and over what timescales, they do so.

Although episodes of mass coral bleaching and mortality will occur in the future, my findings suggest that they may not recur with the frequency and severity predicted by some studies ${ }^{8}$. This should stimulate efforts to protect the remaining threequarters of the world's coral-reef ecosystems ${ }^{9}$ by reducing the compounding effects of anthropogenic factors that are still under our influence.

Andrew C. Baker ${ }^{\star} \dagger$

${ }^{\star}$ Marine Conservation Programs, Wildlife

Conservation Society, 2300 Southern Boulevard,

Bronx, New York 10460, USA

$\dagger$ Center for Environmental Research and

Conservation, Columbia University,

New York 10027, USA

e-mail:abaker@wcs.org

\footnotetext{
1. Rodriguez-Lanetty, M., Cha, H. R. \& Song, J. I. Proc. 9th Int. Coral Reef Symp. (in the press).

2. Goulet, T. L. \& Coffroth, M. A. Proc. 8th Int. Coral Reef Symp. 2, 1331-1334 (1997)

3. Glynn, P. W., Maté, J. L., Baker, A. C. \& Calderón, M. O. Bull. Mar. Sci. 69, 79-109 (2001).

4. Enfield, D. B. Bull. Mar. Sci. 69, 7-25 (2001).

5. Ware, J. R., Fautin, D. G. \& Buddemeier, R. W. Ecol. Model. 84, 199-214 (1996).

6. Toller, W. W., Rowan, R. \& Knowlton, N. Biol. Bull. Mar. Biol. Lab. Woods Hole 201, 360-373 (2001).

7. Kinzie, R. A., Takayama, M., Santos, S. R. \& Coffroth, M. A. Biol. Bull. Mar. Biol. Lab. Woods Hole 200, 51-58 (2001).

8. Hoegh-Guldberg, O. Mar. Freshwat. Res. 50, 839-866 (1999).

9. Wilkinson, C. (ed.) Status of Coral Reefs of the World: 2000 (Austral. Inst. Mar. Sci., Townsville, Queensland, 2000).
}

\section{errata}

Seeing through the face of deception

I. Pavlidis, N. L. Eberhardt, J. A. Levine

Nature 415, 35 (2002)

It was not intended to convey the impression that this thermal-imaging technique is already suitable for mass security-screening purposes: indeed, the false-positive rate identified in this small study might preclude largescale application.

\section{Laterality in tool manufacture by crows}

Gavin R. Hunt, Michael C. Corballis, Russell D. Gray Nature 414, 707 (2001)

The tool held in the beak of the bird shown in Fig. 1 of this communication was wrongly described as a crochet tool, whereas it is a simple leaf-stem tool that happens to be hooked. 